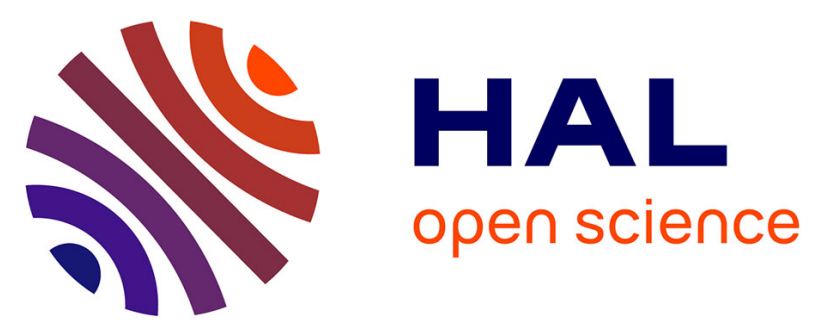

\title{
Community-acquired infectious diarrhoea in children under 5 years of age in Dakar, Senegal
}

Jean-Marie Sire, Benoit Garin, Loïc Chartier, Ndeye Khota Fall, Adama Tall, Abdoulaye Seck, François-Xavier Weill, Sébastien Breurec, Muriel Vray

\section{- To cite this version:}

Jean-Marie Sire, Benoit Garin, Loïc Chartier, Ndeye Khota Fall, Adama Tall, et al.. Communityacquired infectious diarrhoea in children under 5 years of age in Dakar, Senegal. Paediatrics and International Child Health, 2013, 33 (3), pp.139-144. 10.1179/2046905512Y.0000000046 . pasteur02025043

\section{HAL Id: pasteur-02025043}

https://hal-pasteur.archives-ouvertes.fr/pasteur-02025043

Submitted on 11 Mar 2019

HAL is a multi-disciplinary open access archive for the deposit and dissemination of scientific research documents, whether they are published or not. The documents may come from teaching and research institutions in France or abroad, or from public or private research centers.
L'archive ouverte pluridisciplinaire $\mathbf{H A L}$, est destinée au dépôt et à la diffusion de documents scientifiques de niveau recherche, publiés ou non, émanant des établissements d'enseignement et de recherche français ou étrangers, des laboratoires publics ou privés. 
Community-acquired infectious diarrhea among children under five years in Dakar, Senegal

Jean-Marie Sire ${ }^{1,2}$, Benoît Garin ${ }^{2,3}$, Loïc Chartier ${ }^{4}$, Ndeye Khota Fall ${ }^{2}$, Adama Tall ${ }^{5}$, Abdoulaye Seck $^{2}$, François-Xavier Weill ${ }^{6}$, Sébastien Breurec ${ }^{2}$, Muriel Vray ${ }^{4}$

${ }^{1}$ Laboratoire de Microbiologie, Centre Hospitalier Intercommunal de Poissy-Saint-Germain-en-

Laye, Poissy, France, ${ }^{2}$ Laboratoire de Biologie Médicale, Institut Pasteur de Dakar, Dakar, Senegal, ${ }^{3}$ Laboratoire de Bactériologie Expérimentale, Institut Pasteur de Madagascar, Tananarive, Madagascar, ${ }^{4}$ Unité d'Epidémiologie des Maladies Emergentes, Institut Pasteur, Paris, France, ${ }^{5}$ Service d'Epidémiologie, Institut Pasteur de Dakar, Dakar, Senegal, ${ }^{6}$ Unité des Bactéries Pathogènes Entériques, Institut Pasteur, Paris, France

Correspondence to: J-M Sire, Laboratoire de Microbiologie, Centre Hospitalier Intercommunal de Poissy-Saint-Germain-en-Laye, 78303 Poissy, France. Fax: +33 1392744 15; email: jmsire@ chipoissy-st-germain.fr

Running head J-M Sire et al. Infectious infantile diarrhoea in Dakar 
Background: In sub-Saharan Africa, infectious diarrhoea is a major cause of childhood morbidity and mortality. A cross-sectional study was undertaken to document the pathogens potentially involved in community-acquired childhood diarrhoea in Dakar, the capital of Senegal.

Methods: Between September 2007 and March 2008, 176 children aged 1 month to 5 years were recruited consecutively from a primary health care institution in an urban area. Clinical data were recorded and stool samples were collected. Bacterial pathogens were identified using conventional methods and/or PCR assays. Rotaviruses and adenoviruses were detected by a rapid immunochromatographic test. Intestinal parasites were diagnosed by microscopy.

Results: Rotavirus was the most common enteric pathogen, detected in $27 \%$ of patients, followed by Shigella (12\%), diarrhoeagenic Escherichia coli (8\%), enteric adenovirus (8\%), Salmonella (4\%), Campylobacter jejuni (3\%) and Plesiomonas shigelloides (2\%). Mixed bacterial/viral infections were detected in $6 \%$ of cases. Parasites, mostly protozoa, were detected in $14 \%$ of children. Using ipaH PCR, 30\% of samples were positive for Shigella/entero-invasive E. coli. Detection of rotavirus was more frequently associated with younger age groups ( $<24$ months), whereas bacterial diarrhoea was isolated more often in children over 1 year of age. Detection of bacterial pathogens was significantly associated with malnutrition. Antibiotics were prescribed in $77 \%$ of children who attended to the consultation. No pathogen was found in $36 \%$ of them, whereas a virus was detected without any other associated bacterial or parasitic pathogen in $23 \%$.

Conclusion: In developing countries, there is a need to develop reliable, easy-to-use, inexpensive rapid diagnostic tests to guide the management of diarrhoea in infants and children and thereby prevent over-use of antimicrobial agents.

Keywords: Infectious diseases; Community-acquired diarrhoea; Children; Dakar; Senegal

\section{Introduction}


Infectious diarrhoea remains a major cause of morbidity and mortality in developing countries, particularly in children. It has been estimated that in 2010 it accounted for 0.801 million deaths worldwide in children under 5 years. Between 2000 and 2010, deaths from childhood diarrhoea decreased by 0.309 million. ${ }^{1}$ However, the morbidity has not declined, especially in Africa, probably because risk factors (poor hygiene, lack of access to potable water, insufficient promotion of breastfeeding, malnutrition) still prevail. ${ }^{2}$ The continued growth of many major African cities with resulting overcrowding may also contribute to outbreaks of diarrhoea to which children are particularly vulnerable. Data are needed in these urban areas to establish the local epidemiology and implement appropriate preventive measures. We report a cross-sectional study undertaken in a dispensary in central Dakar in order to detect the pathogens and clinical characteristics of community-acquired infantile diarrhoea.

\section{Subjects and Methods}

\section{Patients}

Between September 2007 and March 2008, children aged 1 month to 5 years with acute diarrhoea were enrolled consecutively from the Saint-Martin dispensary, a Catholic mission-run primary health care organisation for maternal/child health in Rebeuss, a poor and densely populated district of central Dakar. Children enrolled had had at least three stools (aqueous, slimy/mucous or bloody) per day, symptoms for $<7$ days, and had not received any antibiotic treatment during the previous 7 days. Clinical examination was undertaken after taking a history from the parents or guardians. Information recorded included age, weight, duration of diarrhoea, symptoms of dehydration, vomiting, number and consistency of stools, and non-specific medication received within the previous week. Growth status was expressed separately for males and females by weight-for-age Z- 
scores (WAZ). ${ }^{3}$ Moderate or severe malnutrition was defined as $\mathrm{WAZ} \leq-2$. Treatment received from the dispensary was recorded. Data were collected by nurses using a case research form (CRF).

\section{Ethical considerations}

Informed consent was obtained from the children's parents or guardians. The study protocol was approved by the Senegalese Health Research National Council.

\section{Laboratory methods}

Stool samples were collected in a sterile plastic vial. A wet smear was microscopically examined for intestinal protozoa trophozoites. Stool samples were delivered within 2 hours to the laboratory of the Institut Pasteur for subsequent processing. A portion of stool was concentrated by the merthiolate iodine formaldehyde concentration technique and examined for helminth eggs and protozoa cysts. $^{4}$ A rapid chromatographic immune-assay detecting simultaneously rotaviruses and enteric adenoviruses was performed (VIKIA Rota-Adeno, bioMérieux, Marcy l'Etoile, France). Stool specimens were inoculated on to Hektoen Enteric agar (Becton-Dickinson, Heidelberg, Germany) to isolate Salmonella and Shigella species, and bromocresol purple lactose agar (BCP) $\underline{\text { (Becton-Dickinson) }}$ to isolate E. coli and other Gram-negative bacteria. Preston broth medium made in the laboratory was inoculated to enrich Campylobacter species and subcultured onto Karmali selective agar (Oxoid, Basingstoke, England). ${ }^{5}$ Muller-Kauffmann tetrathionate broth (Bio-Rad, Marnes-la-Coquette, France) was used to enrich Salmonella and subcultured onto Rambach agar (Merck, Darmstadt, Germany). Serogrouping and serotyping of Shigella isolates were conducted with commercial antisera (Statens Serum Institut, Copenhagen, Denmark and Denka-Seiken, Tokyo, Japan, respectively). Salmonella isolates were serotyped according to the Kauffmann-White 
scheme using commercial antisera (Statens Serum Institut). ${ }^{6}$ Antibiograms were performed by the disc diffusion technique according to the guidelines of the Antibiogram Committee of the French Society for Microbiology (CASFM). E. coli ATCC 25922 was used as the control strain. Vibrio cholerae was not investigated because there were no reported outbreaks during the study duration.

To improve assessment of the real involvement of Shigella in diarrhoea, stool samples were stored at $-20^{\circ} \mathrm{C}$ for subsequent testing by PCR assay based on amplifying the invasion plasmid antigen $\mathrm{H}(\mathrm{ipaH})$ gene, contained in the four Shigella species, as well as in entero-invasive $E$. coli (EIEC). ${ }^{7}$ Shigella flexneri serotype 5 wild-type strain M90T was used as control strain for ipaH PCR. Prior isolation of bacterial DNA was performed using the QIAamp DNA Stool Mini Kit (Qiagen, Courtaboeuf, France).

Strains previously identified as E. coli using the API20E gallery (bioMérieux, Marcy l'Etoile, France) were screened with a single-test multiplex PCR for the presence of 12 genes to differentiate between the six currently recognised diarrhoeagenic E. coli pathotypes. ${ }^{8}$ These pathotypes include enteropathogenic E. coli (EPEC), atypical EPEC (ATEC), Shiga toxinproducing E. coli (STEC), enterotoxigenic E. coli (ETEC), entero-invasive E. coli (EIEC) and entero-aggregative E. coli (EAEC). Atypical EPEC (ATEC) strains harbour the LEE (locus of enterocyte effacement) as EPEC strains, but not the EAF (EPEC adherence factor). Simultaneous detection of E. coli-specific uidA gene was used to confirm biochemical identification of the isolate as E. coli, and to serve as PCR control. ${ }^{8}$

\section{Statistical analysis}

The study population was described as mean (SD) or median [interquartile range] for continuous variables and as percentages for discrete variables. Relations between clinical variables and pathogens were analysed using the Fisher's Exact test. A test for trend across ordered variables was 
used to assess relationships between the different pathogens and patient age. Statistical analysis was performed using the STATA 11 software.

\section{Results}

\section{Population}

Between September 2007 and March 2008, 176 children were recruited consecutively to the study

(Table 1). Fifty-five per cent were male, and the median age was 13 months [IQ1 8, IQ3 20].

Thirty-six per cent were malnourished (Z-score $\leq-2)$. The median number of stools per day was four [IQ1 3, IQ3 5]. Before attending the dispensary, 20\% of children had received oral rehydration salts (ORS), and 23\% had received non-specific anti-diarrhoeal agents (e.g. smectite), anti-motility agents (e.g. loperamide), anti-helminthic agents (e.g. albendazole) or medicinal plants (e.g. guava leaves). Temperature was $\geq 38^{\circ} \mathrm{C}$ in $30 \%$ of cases, there were clinical signs of moderate dehydration (two or more signs of the following: restlessness, sunken eyes, thirst and positive skin pinch test) in $59 \%$, vomiting in $61 \%$, and abdominal pain in $42 \%$. None had severe dehydration. Blood was macroscopically seen in $11 \%$ of stool samples.

[t]TABLE 1[/t]

\section{Pathogens}

At least one of the sought-for pathogens was identified in $105(60 \%)$ children, two pathogens were identified in 25 children, three in two children and four in one child. Bacterial and viral pathogens 
were detected in $48(27 \%)$ and $55(31 \%)$ stools, respectively, while parasitic elements were detected in $25(14 \%)$ samples. Mixed bacterial/viral infections were detected in $11(6 \%)$ children.

The pathogens identified in stool samples are shown in Table 2. Rotavirus was the most prevalent pathogen, detected in $46(27 \%)$ stools, $33(72 \%)$ of them in January. The presence of rotavirus was significantly related to vomiting ( $43 \%$ of children with rotavirus had vomiting vs $10 \%$ of those without rotavirus, $P<0.001)$, absence of blood in stool ( $0 v s 30 \%, P=0.002)$, and normal body temperature ( $32 \%$ vs $8 \%, P=0.001)$, but not to clinical signs of dehydration ( $27 \%$ vs $29 \%$, $P=0.78)$. Enteric adenovirus was found in $13(8 \%)$ patients.

\section{[t]TABLE 2[/t]}

Shigella was isolated from 21 stools (12\%). Sixteen were identified as Shigella flexneri, four as Shigella sonnei biotype g, and one as Shigella boydii serotype 2. Among the 16 isolates of $S$. flexneri, six belonged to the serotype $2 \mathrm{a}$, six to the serotype $1 \mathrm{~b}$, three to the serotype $4 \mathrm{a}$, and one to the serotype 3a. Most of the Shigella isolates were resistant to cotrimoxazole (overall resistance rate 95\%). Rates of resistance of S. flexneri strains to amoxicillin, amoxicillin-clavulanic acid, ticarcillin and chloramphenicol were $44 \%, 44 \%, 44 \%$ and $37 \%$, respectively, whereas all S. sonnei strains were susceptible to these antibiotics. All Shigella strains were susceptible to third-generation cephalosporins (cefotaxime) and quinolones (nalidixic acid, ciprofloxacin). Non-typhi Salmonella enterica, Campylobacter jejuni and P. shigelloides were isolated from seven (4\%), six (3\%) and three $(2 \%)$ stool specimens, respectively. All Salmonella strains were resistant to cotrimoxazole but remained susceptible to aminopenicillins, first- and third-generation cephalosporins, chloramphenicol and quinolones.

The ipaH gene was detected in all 21 Shigella culture-positive specimens and in 30/148 (20\%) culture-negative specimens (DNA amplification failed in seven stools). Since recent advances have confirmed that EIEC and Shigella should be considered a single pathotype of E. coli, 51/169 (30\%) samples could be finally considered positive for the entity Shigella/EIEC. ${ }^{9}$ Presence 
of Shigella/EIEC was significantly associated with blood in the stool $(84 \%$ vs $23 \%, P<0.001)$ and tended to be associated with fever ( $40 \%$ vs $27 \%, P=0.099)$.

Diarrhoeagenic E. coli were detected in 14 children (8\%): EPEC (6 isolates), EAEC (4 isolates), ATEC (2 isolates), ETEC (2 isolates). Neither STEC nor EIEC was detected.

Parasitic agents were detected in 25 (14\%) children, namely Giardia lamblia (15 patients), Entamoeba histolytica/Entamoeba dispar (8), Ascaris lumbricoides (4) and Trichiuris trichiura (1). One patient harboured three different parasites.

Factors associated with pathogens

Table 3 shows the distribution of pathogens amongst the three age groups, 0-12, 13-24 and 25-60 months, respectively. The prevalence of rotavirus was significantly higher in children aged 0-24 months than in those over 24 months $(31 \%$ vs $6 \%, P<0.01)$. Conversely, bacterial pathogens, when considered all together, were significantly less frequent in those aged 0-24 months than in those over 24 months (24\% vs 42\%, $P=0.04$ ). This was particularly so for Shigella. Distribution of diarrhoeagenic E coli strains was not significantly different between the age groups. The prevalence of parasites increased significantly with age. The distribution of pathogens according to nutritional status is shown in Table 4. Moderate or severe malnutrition was significantly related to detection of bacterial pathogens considered as a whole $(P=0.04)$. No significant association was found between rotavirus infection and malnutrition $(P=0.14)$, nor between parasitic detection and malnutrition $(P=0.94)$.

[t]TABLES $3 \& 4[/ t]$

Therapeutic management 
Among the 140 children for whom treatment prescribed in consultation was documented, 108 (77\%) had received antibiotics. Fifty-seven (53\%) had received one antimicrobial agent, 38 (35\%) two, $9(8 \%)$ three and $4(4 \%)$ up to four different antimicrobial agents. One hundred and six (76\%) children received metronidazole for presumed intestinal protozooses, 82 of whom (77\%) also received one or more antibiotics. The most frequently prescribed antibiotics among documented patients were ceftriaxone (51\%) and gentamicin (11\%) by the IM route, and oral amoxicillin/clavulanic acid (26\%) and trimethoprim-sulfamethoxazole (16\%). Among the 108 children treated with antibiotics, no potential pathogen was found in 39 patients (36\%) [in 26 patients (24\%) if we consider results for the detection of Shigella/EIEC by PCR]. A virus was detected without any other associated bacterial or parasitic pathogen in 25 cases (23\%). ORS were prescribed to only six patients.

\section{Discussion}

Since this was not a case-control study, pathogens detected should be considered only as potential pathogens. Nevertheless, it enabled evaluation of the relative importance of different diarrhoeagenic agents in a population of young children living in an urban district of a major West African city.

Rotavirus is a leading cause of severe acute diarrhoea in children under 5 years of age in Africa, ${ }^{10}$ and thus, unsurprisingly, rotavirus was the pathogen most commonly found in our population. A peak in frequency, probably an indicator of an epidemic, was observed in January, one of the coolest and driest months in Dakar. This high frequency during the dry season is consistent with previous studies in neighbouring countries. ${ }^{11,12}$ Detection of rotavirus was more frequently associated with younger age ( $<24$ months). There is evidence that the incidence of rotavirus infection decreases with age because effective immunity conferred by repeated infections

develops gradually. ${ }^{13}$ Moreover, protection against rotavirus is conferred primarily by secretory $\operatorname{IgA}$ 
antibodies located on the surface of the intestinal mucosa. Therefore, maternal antibodies may confer only limited protection against rotavirus during the first months of life. The presence of caliciviruses (i.e. noroviruses and sapoviruses) was not tested in this study. Nevertheless, it is likely that they were involved in some of our cases. Indeed, a recent study in Dakar children hospitalised for acute gastro-enteritis found an $8 \%$ prevalence of caliciviruses. ${ }^{14}$

Shigella is a major public health concern in developing countries, particularly in children, ${ }^{15}$ and was detected by culture in 21 samples (12\%). Its prevalence (identified by conventional culture) is comparable with that found in Dakar in 1993-1994 (11\%). ${ }^{16}$ If, however, we consider the ipaH PCR results, 51 samples were positive for Shigella/EIEC, thus increasing the total percentage of positive stools from $12 \%$ to $30 \%$. Shigella could therefore be considered the most frequently recovered pathogen, suggesting that the true incidence of Shigella in childhood diarrhoea in developing countries may be largely underestimated in studies using only conventional culture techniques. S. flexneri was the most commonly isolated species in our patients, whereas $S$. sonnei was detected less frequently. In contrast with industrialised countries, the predominance of $S$. flexneri over S. sonnei is common in developing countries and has been linked to poor hygiene. ${ }^{17}$ The low number of Shigella isolates limits the significance of antimicrobial susceptibility data. However, the study confirmed a recent report showing that resistance of Shigella to first-line antimicrobials (amoxicillin, amoxicillin-clavulanic acid, chloramphenicol, trimethoprimsulfamethoxazole) is common in Dakar. ${ }^{18}$ In contrast, the latter and our study showed that thirdgeneration cephalosporins and quinolones remained effective.

It is well established that diarrhoeagenic E. coli pathotypes are a major cause of diarrhoea in Africa, especially in children. ${ }^{2}$ Nevertheless, this aetiology is largely unrecognised because few laboratories are able to perform the appropriate identification techniques (i.e. molecular techniques and/or adherence assays). In this study, typical EPEC was the most frequently recovered pathotype (six strains). In addition, two strains of atypical EPEC (ATEC) were detected. EAEC and ETEC pathotypes were also detected (four and two strains, respectively), in contrast with STEC and EIEC. 
Campylobacter is a major cause of childhood diarrhoea in developing countries, especially in children under 2 years of age. ${ }^{19}$ We found this pathogen in $3 \%$ of cases, a result consistent with prevalences reported in previous studies in West Africa. ${ }^{12,20}$

Diarrhoea associated with bacteria, particularly Shigella, affected children over 1 year of age more commonly. This might be explained by the protection conferred by maternal antibodies during the 1st year of life. We found no particular tendency for diarrhoeagenic E. coli. The relationship between malnutrition and severity of diarrhoea is well recognised, especially because of the immune system deficiency caused by inadequate intake of micronutrients such as zinc. ${ }^{21}$ In this study, the detection of bacterial pathogens was significantly associated with malnutrition but not with the detection of rotavirus and parasites.

Parasitic agents were mainly protozoa (Giardia lamblia, E. histolytica/E. dispar), while helminth eggs were rarely detected. This low prevalence of helminthiasis may be owing to the young age of the children. A study in Senegal in 2002 showed that the rate of helminth infestation was highest in children between 11 and 15 years of age. ${ }^{22}$ The prevalence of parasites (both protozoa and helminths) in this study also tended to increase with age. Another reason for this low prevalence of helminths in our population might be that a number of children had received antihelminthics before coming for consultation. It is noteworthy that we did not investigate for Cryptosporidium species in our study. This pathogen was significantly associated with childhood diarrhoea in West Africa. ${ }^{23}$

The majority of children presented with signs of mild or moderate dehydration. No cases of severe dehydration were recorded, probably because they were directly hospitalised in paediatric wards.

Of those children with documented antibiotic treatment prescribed in consultation, a virus (rotavirus or adenovirus) was detected without any other associated pathogen in $23 \%$ of cases. Moreover, no pathogen was found in $36 \%$ of children. Although this rate could be reduced to $24 \%$ when the results of PCR ipaH for detecting Shigella are considered, antibiotic treatment was 
unnecessary in approximately half of the cases. This over-use of antibiotics is of concern because it promotes the emergence of antibiotic resistance. It also represents a significant cost to families.

This report underscores that accurate evaluation of pathogens in childhood diarrhoea in developing countries requires the integration of advanced methods that complement existing tools. Moreover, it highlights the need for primary health care facilities to perform certain simple tests that assess the appropriateness of antibiotic treatment. Microscopic examination of stools can be done easily if staff are trained in basic parasitology. At the same time, however, simple, reliable and inexpensive diagnostic tools for detecting other pathogens, especially bacteria, are needed.

Immunochromatographic tests (dipsticks) are being developed for S. flexneri 2 a and $S$

dysenteriae $1 .^{24,25}$ These tools, although promising, require further evaluation in routine practice. They also need to be developed for other pathogens, particularly other species of Shigella and diarrhoeagenic E. coli.

\section{Acknowledgment}

The authors thank Natasha Dubois-Cauwelaert, Alice Dufougeray and Fatou Bintou Dièye for technical help.

\section{References}

1 Liu L, Johnson HL, Cousens S, Perin J, Scott S, Lawn JE, et al. Global, regional, and national causes of child mortality: an updated systematic analysis for 2010 with time trends since 2000 Lancet. 2012;379:2151-61.

2 Okeke IN. Diarrheagenic Escherichia coli in sub-Saharan Africa: status, uncertainties and necessities. J Infect Dev Ctries. 2009;3:817-42.

3 Kuczmarski RJ, Ogden CL, Guo SS, Grummer-Strawn LM, Flegal KM, Mei Z, et al. 2000 CDC growth charts for the United States: methods and development. Vital Health Stat 11. 2002;246:1-190.

4 Blagg W, Schloegel EL, Mansour NS, Khalaf GI. A new concentration technique for the demonstration of protozoa and helminth eggs in feces. Am J Trop Med Hyg. 1955;1:23-8.

5 Bolton FJ, Robertson L. A selective medium for isolating Campylobacter jejuni/coli. J Clin Pathol. 1982;35:462-7. 
6 Grimont PAD, Weill FX. Antigenic formulae of the Salmonella serovars. WHO Collaborating Center for Reference and Research on Salmonella, 9th edn. Paris: Institut Pasteur, 2007. Available from http://www.pasteur.fr/ip/portal/action/WebdriveActionEvent/oid/01s-000036089.

7 Sethabutr O, Venkatesan M, Murphy GS, Eampokalap B, Hoge CW, Echeverria P. Detection of Shigellae and enteroinvasive Escherichia coli by amplification of the invasion plasmid antigen H DNA sequence in patients with dysentery. J Infect Dis. 1993;167:458-61.

8 Müller D, Greune L, Heusipp G, Karch H, Fruth A, Tschäpe H, et al. Identification of unconventional intestinal pathogenic Escherichia coli isolates expressing intermediate virulence factor profiles by using a novel single-step multiplex PCR. Appl Environ Microbiol. 2007;73:3380-90.

9 Lan R, Alles MC, Donohoe K, Martinez MB, Reeves PR. Molecular evolutionary relationships of enteroinvasive Escherichia coli and Shigella spp. Infect Immun. 2004;72:5080-8.

10 Waggie Z, Hawkridge A, Hussey GD. Review of rotavirus studies in Africa: 1976-2006. J Infect Dis. 2010;202 (suppl):23-33.

11 Hanlon P, Hanlon L, Marsh V, Byass P, Shenton F, Sanders RC, et al. Epidemiology of rotavirus in a periurban Gambian community. Ann Trop Paediatr. 1987;7:238-43.

12 Mølbak K, Wested N, Højlyng N, Scheutz F, Gottschau A, Aaby P, et al. The etiology of early childhood diarrhea: a community study from Guinea-Bissau. J Infect Dis. 1994;169:581-7.

13 Velázquez FR, Matson DO, Calva JJ, Guerrero L, Morrow AL, Carter-Campbell S, et al. Rotavirus infections in infants as protection against subsequent infections. N Engl J Med. 1996;335:1022-8.

14 Ka R, Diop A, Dia ML, Diop D, Sow AI, Cissé MF. Calicivirus gastroenteritis in children hospitalized in Dakar. Med Mal Infect. 2011;41:108-9.

15 Kotloff KL, Winickoff JP, Ivanoff B, Clemens JD, Swerdlow DL, Sansonetti PJ, et al. Global burden of Shigella infections: implications for vaccine development and implementation of control strategies. Bull WHO. 1999;77:651-66.

16 Gassama A, Boye CS, Aidara A, Raphenon G, Sam A, Mboup S. Shigella in Senegal (19931994): distribution through serovar, sensibility to antibiotics and virulence. Med Mal Infect. 1997;27:267-70.

17 World Health Organization. Antimicrobial Resistance in Shigellosis, Cholera and Campylobacteriosis, 2001. Available from http://www.who.int/drugresistance/Antimicrobial_resistance_in_shigellosis_cholera_and_cam.p df

18 Sire JM, Macondo EA, Perrier-Gros-Claude JD, Siby T, Bahsoun I, Seck A, et al. Antimicrobial resistance in Shigella species isolated in Dakar, Senegal (2004-2006). Jpn J Infect Dis. 2008;61:307-9.

19 Coker AO, Isokpehi RD, Thomas BN, Amisu KO, Obi CL. Human campylobacteriosis in developing countries. Emerg Infect Dis. 2002;8:237-44.

20 Koulla-Shiro S, Loe C, Ekoe T. Prevalence of Campylobacter enteritis in children from Yaounde (Cameroon). Cent Afr J Med. 1995;41:91-4.

21 Podewils LJ, Mintz ED, Nataro JP, Parashar UD. Acute, infectious diarrhea among children in developing countries. Semin Pediatr Infect Dis. 2004;15:155-68.

22 Ndir I, Gaye A, Sy M, Gaye O, Ndir O. Prevalence of intestinal parasites at the King Baudouin health center of Guediawaye (Senegal). Dakar Med. 2002;47:168-71.

23 Opintan JA, Newman MJ, Ayeh-Kumi PF, Affrim R, Gepi-Attee R, Sevilleja JE, et al. Pediatric diarrhea in southern Ghana: etiology and association with intestinal inflammation and malnutrition. Am J Trop Med Hyg. 2010;83:936-43.

24 Nato F, Phalipon A, Nguyen TL, Diep TT, Sansonetti P, Germani Y. Dipstick for rapid diagnosis of Shigella flexneri 2a in stool. PLoS One. 2007;2:e361.

25 Taneja N, Nato F, Dartevelle S, Sire JM, Garin B, Thi Phuong LN, et al. Dipstick test for rapid diagnosis of Shigella dysenteriae 1 in bacterial cultures and its potential use on stool samples. PLoS One. 2011;6:e24830. 
Table 1 Characteristics of the 176 children enrolled in the study

Characteristics

$n(\%)$

Male

Age, mths*

$97(55)$

Z-score*

$13[8,20]$

$\leq-2(19$ missing $)$

$-1.3[-2.6,-0.4]$

Duration of diarrhoea*, days

$56(36)$

Number of stools per day*

$3[3,6]$

$4[3,5]$

Received previous ORS ${ }^{\dagger}$ therapy (13 missing)

$33(20)$

Received previous non-specific medication (1

$41(23)$

missing)

Received one or more antibiotics in consultation

$108(77)$

(36 missing)

Body temperature $\geq 38^{\circ} \mathrm{C}$ ( 8 missing)

$50(30)$

Symptoms of moderate dehydration (14 missing) 96 (59)

Vomiting (19 missing)

$96(61)$

Abdominal pain (35 missing)

$59(42)$

Blood in stool

$20(11)$

* Median [IQ1, IQ3]; ${ }^{\dagger}$ oral rehydration salts. 
Table 2 Enteric pathogens detected in 176 children aged $<5$ years attending Saint-Martin Dispensary

\begin{tabular}{lll} 
Cause & Pathogen & $n(\%)$ \\
& & \\
\multirow{3}{*}{ Bacteria } & Diarrhoeagenic E. coli & $14(8)$ \\
& EPEC & 6 \\
& EAEC & 4 \\
& ATEC & 2 \\
& ETEC & 2 \\
& Shigella spp. & $21(12)$ \\
& S. flexneri & 16 \\
& S. sonnei & 4 \\
& S. boydii & 1 \\
& Salmonella spp. & $7(4)$ \\
& Campylobacter jejuni & $6(3)$ \\
& Plesiomonas shigelloides & $3(2)$ \\
Viruses* & Rotavirus & $46(27)$ \\
& Adenovirus & $13(8)$ \\
Parasites & Giardia lamblia & $15(9)$ \\
& E. histolytica/E. dispar & $8(5)$ \\
& Ascaris lumbricoides & $4(2)$ \\
& Trichiuris trichiura & $1(<1)$ \\
& & \\
\hline
\end{tabular}

* Data missing for five patients. 
Table 3 Distribution of identified pathogens according to age

\begin{tabular}{|c|c|c|c|}
\hline Organism & Age group, mths & No. $(\%)$ of children infected & $P$-value \\
\hline \multirow[t]{3}{*}{ Rotavirus $(n=46)$} & $0-12$ & 29/81 (36) & $<0.01$ \\
\hline & $13-24$ & $15 / 59(25)$ & \\
\hline & $25-60$ & $2 / 31(6)$ & \\
\hline \multirow[t]{3}{*}{ Bacteria* (all species) $(n=48)$} & $0-12$ & $18 / 85(21)$ & 0.03 \\
\hline & $13-24$ & $17 / 60(28)$ & \\
\hline & $25-60$ & $13 / 31(42)$ & \\
\hline \multirow[t]{3}{*}{$\underline{\text { Shigella } \operatorname{spp}^{*}(n=21)}$} & $0-12$ & $4 / 85(5)$ & $<0.01$ \\
\hline & $13-24$ & $10 / 60(17)$ & \\
\hline & $25-60$ & $7 / 31(23)$ & \\
\hline \multirow[t]{3}{*}{ Shigella/EIEC ${ }^{\dagger}(n=51)$} & $0-12$ & $17 / 80(21)$ & $<0.01$ \\
\hline & $13-24$ & $20 / 58(34)$ & \\
\hline & $25-60$ & $14 / 31(45)$ & \\
\hline \multirow[t]{3}{*}{ Diarrhoeagenic E. coli $i^{\ddagger}(n=14)$} & $0-12$ & $9 / 85(11)$ & 0.17 \\
\hline & $13-24$ & $4 / 60(7)$ & \\
\hline & $25-60$ & $1 / 31(3)$ & \\
\hline \multirow[t]{3}{*}{ Parasites $(n=25)$} & $0-12$ & $7 / 85(8)$ & 0.01 \\
\hline & $13-24$ & $10 / 60(17)$ & \\
\hline & $25-60$ & $8 / 31(26)$ & \\
\hline
\end{tabular}

* Identified by culture; ${ }^{\dagger}$ determined by ipaH PCR; ${ }^{\ddagger}$ selected by culture and confirmed by multiplex PCR. 
Table 4 Distribution of identified pathogens according to nutritional status ( $n=157,19$ missing values)

\begin{tabular}{|c|c|c|c|}
\hline Organism & $\begin{array}{l}\text { Normal nutritional status } \\
n=101(\%)\end{array}$ & $\begin{array}{l}\text { Malnourished } \\
n=56(\%)\end{array}$ & $P$-value \\
\hline Rotavirus $(n=42)$ & 31/98 (32) & $11 / 54(20)$ & 0.14 \\
\hline Bacteria* (all species) $(n=41)$ & $21 / 101(21)$ & $20 / 56(36)$ & 0.04 \\
\hline Shigella $\operatorname{spp}^{*}(n=17)$ & $8 / 101(8)$ & $9 / 56(16)$ & 0.12 \\
\hline Shigella/EIEC ${ }^{\dagger}(n=42)$ & $24 / 97(25)$ & $18 / 53(34)$ & 0.23 \\
\hline Diarrhoeagenic E. coli $(n=13)$ & $5 / 101(5)$ & $8 / 56(14)$ & 0.07 \\
\hline Parasites $(n=22)$ & 14/101 (14) & $8 / 56(14)$ & 0.94 \\
\hline
\end{tabular}

* Identified by culture; ${ }^{\dagger}$ determined by ipaH PCR; ${ }^{\ddagger}$ selected by culture and confirmed by multiplex PCR. Normal nutritional status was defined as weight-for-age Z-score $>-2$, moderate or severe malnutrition as weight-for-age Z-score $\leq-2$. 